\title{
A RELAÇÃO ENTRE PARTICULARIDADES CONTEXTUAIS E A PERCEPÇÃO DA SEGURANÇA NA ÁREA CENTRAL DE MANAUS (AM)
}

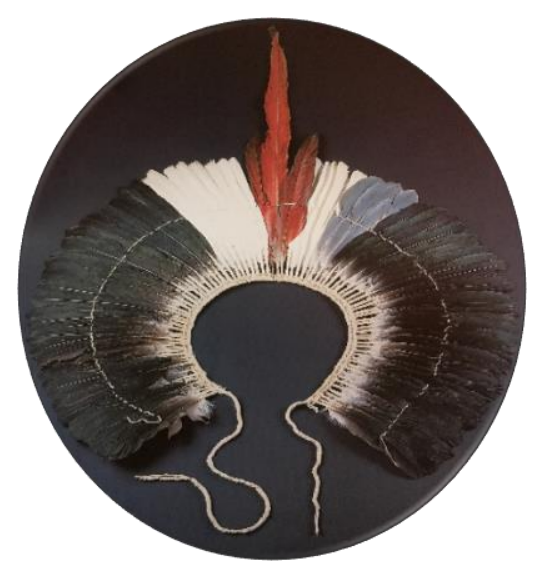

Josué Gomes Vieira ${ }^{1}$ Walmir de Albuquerque Barbosa ${ }^{2}$

RESUMO: Baseando-se nos dados coletados por uma pesquisa de vitimização realizada com 618 Microempreendedores Individuais (MEI) das Galerias Comerciais da Área Central de Manaus (AM), o presente artigo objetiva compreender a relação entre as particularidades contextuais dos trabalhadores urbanos das Galerias Comerciais com a percepção da segurança na Área Central de Manaus (AM).

PALAVRAS-CHAVE: Manaus. Área Central. Criminalidade. Vitimização. Segurança

1 Doutorando em Sociedade e Cultura na Amazônia, pelo Programa de PósGraduação em Sociedade e Cultura na Amazônia, da Universidade Federal do Amazonas (PPGSCA-UFAM)

2 Doutor em Comunicação (USP); Professor do Programa de Pós-Graduação em Sociedade e Cultura na Amazônia, da Universidade Federal do Amazonas (PPGSCA-UFAM) 


\section{INTRODUÇÃO}

Nos 30 anos finais do século XX e na primeira década do XXI, as agências estatísticas de ordem censitária, educacional, militar e de saúde pública, realizaram profundos estudos sobre o aumento da criminalidade na sociedade brasileira. Este impulso acompanhou tendências internacionais, principalmente oriundas de academias e institutos científicos sediados nos Estados Unidos, Inglaterra, Alemanha, França (CERQUEIRA, LOBÃO e CARVALHO, 2005; SENASP, 2012).

Conforme dados do Mapa da Violência, o Brasil figura entre os cinco da América com as maiores taxas de mortes por homicídio, os Estados de São Paulo, Rio de Janeiro, Alagoas, Paraná e Rio Grande do Norte, são os cinco Estados brasileiros com maior índice de vitimização por crime do Brasil. Manaus ocupa a $17^{\circ}$ posição entre as capitais brasileiras com maior índice de mortes ocasionadas pelo crime, quanto a roubo, furto e violência a cidade fica na $14^{\circ}$ posição entre as capitais com maiores registros criminais dessa natureza (WAISELFISZ, 2013; 2014).

Estatisticamente esses números tornam-se preocupantes em uma cidade com 2.020.301 de habitantes, a mais populosa da Região Norte e a $7^{\circ}$ no ranking das cidades mais populosas do Brasil (IBGE, 2015), desse quantum, 1.538 .114 são economicamente ativos, dos quais 758.239 trabalham no setor de serviços, e 476.098 na iniciativa privada, como Micro Empresário (ME) e Micro Empreendedor Individual (CMEI), que possivelmente em 10 anos Manaus (AM) pode figurar entre os 10 municípios mais violentos do Brasil (WAISELFISZ, 2014).

Com a falência da Zona Franca Comercial localizada na Área Central de Manaus no final da década de 80, a cidade se viu diante de um dilema social ocasionado pela evasão da população urbana para outras áreas da 
cidade e um rearranjo no mobiliário predial que ao longo dos anos foi ocupado por populações vulneradas pela inacessibilidade ao trabalho formal ou foram postos à locação preferencialmente comercial por seus proprietários. Nascimento (2011) aponta que entre 1985-2009 essa Região teve um aumento significativo de furtos, roubos, estupros e violência domestica, creditando as causas desse aumento à alta rotatividade populacional, ao baixo nível de pertencimento dos indivíduos com o local e a formação de pontos de atratividade delituosa na Área Central.

Baseando-se nos resultados de um estudo dos condicionamentos da vitimização na Área Central de Manaus (AM), especificamente da relação entre as particularidades contextuais e a percepção da segurança, o presente artigo se atem na relação entre particularidades estruturais da Area Central de Manaus e a percepção de uma amostra de trabalhadores urbanos sobre a segurança. Utiliza-se como base empírica os resultados de uma investigação sobre criminalidade e processo de vitimização em uma amostra populacional urbana de 618 trabalhadores abrigados em quatro Centros de Compras populares, Galeria Espírito Santo $(\mathrm{n}=155)$, Galeria Epaminondas $(\mathrm{n}=153)$, Galeria dos Remédios $(\mathrm{n}=155)$ e Galeria Floriano Peixoto ( $\mathrm{n}=155$ ) localizadas na Área Central de Manaus, Amazonas.

Como pode notar o objeto analisado neste estudo localiza-se em um panorama conflituoso gerado pelas relações de poder no uso econômico do solo urbano, onde a sociabilidade violenta moldou novas relações e formas de ocupação da Área Central de Manaus (AM). Primeiro porque a amostra populacional pesquisada, "camelôs", possui uma trajetória histórica e social ascendente na Área Central de Manaus (AM). Em 40 anos de presença na Área Central de Manaus (AM) o "camelô" saltou da "ilegalidade", por sua condição de informalidade empregatícia, para uma ocupação amparada por leis trabalhistas, sendo atualmente categorizado de "Microempreendedor Individual" (CMEI). 
Segundo, na constituição sócio-histórica da Área Central de Manaus (AM) o Microempreendedor Individual, tipo trabalhador urbano das Galerias Comerciais entrevistado na pesquisa, é uma identidade urbana que carrega nas suas experiências de vida o compartilhamento existencial entre a ideia de "ilegal"/crime e "trabalhador", dando a ele mobilidade mais flexível para se locomover pelo urbano da Área Central de Manaus (AM) em comparação com outras identidades do local; ora desempenhando funções laborais e ora cumprindo papel estratégico de sujeito do meio na criminalidade, seja como delituoso, vitima ou trabalhador.

Terceiro, devido ao processo de revalorização econômica da Área Central, os "camelôs" remanejados para as quatro Galerias Comerciais são portadores de uma história de choques e conflitos pelo uso do solo urbano, carregam consigo marcas produzidas pelas formas de controle social da "ilegalidade", do crime e ao mesmo tempo de praticas delituosas muitas vezes não comunicadas às policias, tornando-os agentes de centro em um processo desigual de sociabilidade, de urbanização, de acesso ao trabalho e renda numa das mais importantes cidades da Amazônia Brasileira.

A pesquisa foi construída em um modelo survey de vitimização aplicada na amostra de trabalhadores urbanos albergados nas Galerias Comerciais, os assuntos criminalidade e o de vitimização são entendidos como condicionantes e determinantes das noções de "atratividade delituosa" (NEWMAN, 1972; REPPETO, 1974) e de "oportunidade de vitimização" (COHEN e FELSON, 1979), pois essas noções aparecem nos elementos testemunhais da pratica delituosa e na fala do trabalhador-vitima.

A partir dessas observações identifica-se que o processo sóciohistórico de consolidação do antigo "camelô" em Microempreendedor Individual na Área Central de Manaus (AM) detém um acumulo de experiências sociais em conflitos produzidos pelo choque entre a ilegalidade profissional, a permissividade laborativa e o crime, que quando investigados 
pela pesquisa de vitimização apresentam dados empíricos valiosos para compreender a associação entre paisagem urbana, vitimização e criminalidade, onde o ponto de maior convergência é na relação casuística entre as particularidades ambientais e contextuais da Área Central de Manaus (AM) com a percepção da segurança de uma das identidades circulantes no local.

Pesquisas dessa natureza se alinham a tendências contemporâneas de analise da criminalidade e da sensação de segurança/insegurança, como as que são realizadas desde a década de 1980 que tentam compreender a violência como um fenômeno social crescente na sociedade brasileira (ZALUAR, 1999; MISSE, 1999; VELHO, 2000; MACHADO DA SILVA, 2008), bem como a de tendências mais recentes como a que foi realizada entre 2010 e 2012 pela Secretaria Nacional de Segurança Pública (SENASP/MJ), pela qual detectou intensa carência nos dados da Região Norte no que competia à vitimização por delitos praticados em zonas urbanas (SENASP, 2012).

\section{2 - NOTAS DA PESQUISA DE VITIMIZAÇÃO REALIZADA NA ÁREA CENTRAL DE MANAUS (AM)}

Debitaria do pressuposto técnico de que há um padrão distributivo da delinquência e da vitimização na população, a analise estatística aliada a analise social na pesquisa criminológica prima pela quantificação da incidência criminal e pela qualificação da prevalência delitiva nos grupos e subgrupos sociais. Em se tratando de avaliações e do desenvolvimento de pesquisas cientificas sobre a criminalidade esses dois critérios estatísticos são elementos essenciais para interpretação da dinâmica social do crime, da formulação de teorias criminológicas e, em plano estrutural, estimulam a 
criação de políticas de segurança públicas mais eficientes e diretivas por localizar nos espaços sociais os grupos delitivos, as praticas de crimes e as populações vulneradas pela insegurança e o medo da violência.

Para Mosher et. all (2002) é valido considerar na analise criminal a existência de "crimes" e não de "crime" devido a concorrência de modelos analíticos que objetivam explicar a dinâmica social e as formas de violência como emaranhados complexos que despertam a criação de políticas publicas de controle com intervenção de praticas de prevenção. Dar visibilidade técnica a essa distinção na analise criminal é explicar o crime pela interpretação dos perfis dos ofensores e das vitimas pertencentes a um determinado contexto social, econômico e cultural regido por condutas e códigos "normais" mantidos por agencias de controle, capazes de estimular respostas sociais e institucionais de enfrentamento do fenômeno criminal.

A mensuração do crime por metodologias de analise social depende essencialmente da teoria criminológica que o ampara, cabe a cada uma fundamentar um modelo metodológico próprio de explicação do fenômeno criminal, seja o baseado em dados oficiais: como pesquisas abalizadas em dados de mortalidade populacional, nos boletins de ocorrência policial e nos registros judiciais e prisionais. Ou seja em pesquisas corporificadas em dados coletados por métodos extraoficiais que se amparam na proposta interdisciplinar de analise, como os surveys com os criminosos e os realizados com as vitimas de crimes (SILVA, 2004; ZILLI, 2004).

Maguire (2002) afirma que os mecanismos técnicos de determinação e qualificação do crime, da violência são múltiplos e complementares, eles não se excluem um do outro. Uma teoria que abrace a totalidade do crime e explique de forma coesa todas as dinâmicas sociais não existe, apesar de haver iniciativas totalizantes, mas o mapeamento construído por elas carece de particularidades do fenômeno que o tornam complexo. Cada pesquisa possui seu limite metodológico, teórico e ético, sua dificuldade operacional, 
sua consistência estatística e interpretativa, sua coerência e utilidade publica. Epistemologicamente em termos quantitativos não há um numero que represente o totalizante real do crime; sim fontes e métodos que se auto complementam e se atualizam nas premissas da incidência e prevalência.

Referindo-se às bases de pesquisa criminais no Brasil, Tulio Kahn (2000) diz que as únicas bases fidedignas de mensuração do crime são de quatro tipos e de natureza complementar, 1) as bases registrais do sistema de justiça criminal, B.O., R.O., processos judiciais; 2) repositórios epidemiológicos de saúde; 3) surveys de autorreportagem com autores de crimes; 4) surveys com as vitimas de crime.

Essa pesquisa acredita que uma importante pesquisa constituída nas bases de dados complementares às fontes oficiais de investigação criminal seja a Pesquisa de Vitimização por se ater fundamentalmente nos dark numbers (cifras ocultas) do crime, por sua metodologia de analise ir além das variantes respostas dos registros oficiais, e por se aprofundar na microssociologia dos processos de vitimização não relatados às policias, ou quando informados não registrados pelos agentes de policia por alguma razão que escapa os processos administrativo (CATÃO, 2000; KAHN, 2000; LANGTON, 2012).

As primeiras pesquisas de vitimização foram implementadas nos Estados Unidos na década de 1960 com a finalidade de mapear os crimes que não chegavam ao conhecimento policial pelo registro formal nos departamentos de policias. Àquela época considerou que esses tipos de crimes compunham uma vasta base oculta de acontecimentos criminais que não chegavam ao conhecimento da policia por diversas razões sociais e institucionais que brecavam a prevenção ou enfrentamento do crime.

À época, quando os crimes inscritos nessa categoria foram interpretados ganharam a alcunha de "cifras ocultas" do crime. A 
compreensão da dinâmica desses crimes, em alguns casos chegavam a complementar os dados oficiais já produzidos pelos departamentos de policia, uma vez que o entendimento sobre o crime e o criminoso deixavam de ser tratados isolados, passando a ser considerados construções sociais sujeitas aos processos de expansão e condensação do crime nos grupos e subgrupos sociais, por isso as pesquisas necessitavam ser atualizadas constantemente a partir da elaboração e mensuração de novas técnicas de pesquisas sociais dos determinantes locais da pratica delitiva (LANGTON, 2012).

Portanto, as pesquisas de vitimização são investigações impulsionadas pelos estudos dos grupos desviantes como as que foram realizadas por Erwin Goffman (1962) no estudo sobre as classes sociais estigmatizadas e pelo estudo de Howard Becker (1967) sobre a conduta desviante como técnica de afirmação grupal na sociedade, e pela especialização teórico-metodológica da “teoria da desorganização social" que desde os anos 60 do século XX auxilia os analistas criminais a organizar os números da criminalidade na dinâmica social de determinados contextos e entender informações sociais que amparam o contexto da criminalidade como uma organização social de crimes subnotificados ou não notificados às policias (BEATO, 1998; LANGTON, 2012; SENASP-MJ, 2013).

As recentes pesquisas de vitimização realizadas pelo National Crime Victimization Survey (NCVS) e pelo International Crime Victims Survey (ICVS) consideram a pesquisa de vitimização um mecanismo sistêmico importante para o estudo e compreensão do crime como uma construção social de grupos sociais delitivos e vulnerados pelos riscos ocasionados pela criminalidade, pois objetivam organizar informações pertinentes à experiência individual com o crime, das condições de ocorrência, do sentimento de segurança/insegurança e da violência cometida (VAN DIJK, 2008). 
Nesse percurso crê-se que o estudo dos surveys de vitimização obtidos com as estimativas dos desdobramentos do crime comunicado registrado, do crime não comunicado e/ou do crime comunicado não-registrado. A frequência e a natureza amostradas na pesquisa de vitimização apresentam informações dos perfis vitimologicos, dos ofensores, dos potenciais ofensores, das circunstancias temporais e ambientas do cometimento delitivo, e das informações suplementares da experiência da vitima com o sistema de justiça criminal e dos mecanismos de autodefesa utilizados pelas populações como medida de controle social da criminalidade (MAGUIRE, 2002; MOSHER et all, 2002).

Alem da estimação dos índices criminais numa dada população as pesquisas de vitimização inserem-se nas Ciências Sociais, Sociais Aplicadas e Humanas como estudos metodológicos e teóricos das circunstancias do crime, importante para elaboração epistêmica e técnica de políticas de enfrentamento e prevenção em segurança ao oferecer dados mais próximos da realidade capazes de localizar na malha social os conflitos, as identidades, as condições de amparo social do crime e os riscos ocasionados pelas praticas delitivas, bem como das omissões institucionais com a não resolução dos problemas secundários ao delito. Essas informações organizadas permitem o analista criminal mapear a frequência dos cometimentos delitivos, identificar grupos delinquentes e outros vulnerados pelas ações criminosas e determinar os ambientes e identidades propensos à pratica de violência letal, como o homicídio (PINTO et all, 2007; VAN DIJK et all, 2008).

Kahn (op. cit), Langton (2012) e Van Dijk et all (2008) concordam que as pesquisas de vitimização necessitam de um tratamento metodológico único e com periodicidade de atualização anual, pois a base de dados resultante pode servir para os departamentos de segurança publica como um mecanismo exógeno de aferição e controle dos dados oficiais organizado pelas policias. Com isso aferir o nível de confrabilidade técnica das medidas 
preventivas implementadas nos grupos sociais, pois os dados reais sobre o processo de vitimização pode ser é destinado a formulação de técnicas de prevenção de futuras vitimas a partir da socialização dessas técnicas como instrumentos de resolução de conflitos interpessoais onde o alcance policial é mínimo.

Apresentando natureza quantitativa e probabilística a Pesquisa de Vitimização realizada com trabalhadores urbanos das Galerias Comerciais da Area Central de Manaus (AM) utilizou a abordagem domiciliar do trabalho e da residência na Região Central de Manaus. Como universo de pesquisa, entrevistou homens e mulheres com idade igual ou superior a 16 anos tipificados por Micro Empreendedores Individuais (MEI), trabalhadores nas Galerias Comerciais Municipais e residentes nos bairros da Área Central de Manaus, Amazonas, a unidade de pesquisa é o trabalhador urbano Microempreendedor Individual (MEI).

Considerou-se "trabalhadores" homens e mulheres com idade de 16 anos ou mais inscritos como Microempreendedores Individuais (MEI), que realizam por conta própria sua atividade ocupacional remunerada e se legaliza como pequeno empresário com base na Lei Complementar $n^{\circ} .128$ de 19 de dezembro de 2008, que fatura em sua ocupação no máximo até $\mathrm{R} \$$ 60.000,00 (sessenta mil reais) por ano e não tem participação em outra empresa como sócio ou titular.

A pesquisa considerou "Galeria Comercial" os estabelecimentos provisórios e permanentes construídos pela Prefeitura de Manaus entre 2013 e 2014 para abrigar os trabalhadores informais de rua conhecidos como "camelôs". Fruto de um Projeto de Revitalização, Ordenamento e Requalificação do mobiliário urbano do Centro de Manaus, administrado pela Prefeitura de Manaus, a construção dessas Galerias visou qualificar, organizar e legalizar a mão-de-obra informal localizadas na Área da antiga Zona Franca Comercial. 
Considerando as definições metodológicas formuladas pelo ICVSUNICRI e concordando com a metodologia utilizada na Pesquisa Nacional de Vitimização da SENASP-MJ para seu plano amostral, a presente pesquisa opta por utilizar a técnica estatística de amostragem probabilística para montagem do seu plano amostral. Justifica-se a escolha dessa técnica, por considerarmos as restrições operacionais e financeiras para realização de uma pesquisa em grande escala focada no mapeamento completo dos domicílios comerciais e residenciais da Área Central de Manaus (AM) através de uma operação censitária.

O uso da técnica de amostragem probabilística para tipos de pesquisas populacionais como a presente que tende a facilitar a demonstração representativa da vitimização em um determinado espaço urbano, oferece ao analista aspectos representativos da população como um todo. A definição do universo da pesquisa, a formulação do plano de amostragem e a seleção das unidades da amostra compõe um quadro técnico importante para se ler um dado especifico da sociedade como um todo a partir da seleção de uma amostra populacional.

Assim, o plano amostral da pesquisa de vitimização com trabalhadores da Galerias Comerciais baseia-se nos múltiplos estágios que o universo da pesquisa apresenta. Primeiro o lugar Área Central onde se localizam as Galerias Comerciais que correspondem aos estratos da pesquisa onde cada unidade foi disposta a partir da localização e área de influência geográfica de cada Galeria Comercial dentro do lugar, o que possibilita estimar variáveis de interesse empírico para o domínio geográfico de cada Galeria Comercial com uma medida de precisão controlada, assim a pesquisa considera a Área Central uma Região de Vitimização e as Galerias Comerciais seus estratos. 


\begin{tabular}{|c|c|c|c|}
\hline $\begin{array}{c}\text { REGIÃO DE } \\
\text { VITIMIZAÇÃO }\end{array}$ & ESTRATO & $\begin{array}{c}\text { POPULAÇÃO } \\
\text { (MEI) }\end{array}$ & $\begin{array}{c}\text { AMOSTRA } \\
\text { (MEI) }\end{array}$ \\
\hline \multirow{4}{*}{$\begin{array}{c}\text { ÁREA } \\
\text { CENTRAL }\end{array}$} & $\begin{array}{c}\text { Galeria dos } \\
\text { Remédios }\end{array}$ & 175 & 155 \\
\cline { 2 - 4 } & $\begin{array}{c}\text { Galeria Floriano } \\
\text { Peixoto }\end{array}$ & 175 & 155 \\
\cline { 2 - 4 } & $\begin{array}{c}\text { Galeria Espírito } \\
\text { Santo }\end{array}$ & 175 & 155 \\
\cline { 2 - 4 } & $\begin{array}{c}\text { Galeria } \\
\text { Epaminondas }\end{array}$ & 175 & 153 \\
\hline
\end{tabular}

TABELA 1: DISTRIBUIÇÃO ESTRATO, POPULAÇÃO E AMOSTRA FONTE: Planejamento da Pesquisa

Como Região de Vitimização a Área Central de Manaus (AM) estratificada pela posição geográfica das quatro Galerias Comerciais, Galeria dos Remédios com uma população de 175 MEI e uma amostra da pesquisa de 155 MEI; Galeria Floriano Peixoto com uma população de 175 MEI e uma amostra da pesquisa de 155 MEI; Galeria Espirito Santo com uma população de 175 MEI e uma amostra da pesquisa de 155 MEI e a Galeria Epaminondas com uma população de 175 MEI e uma amostra da pesquisa de 153 MEI, como dispôs o quadro abaixo:

O questionário como instrumento de coleta de dados utilizado nesta pesquisa teve por inspiração a metodologia o instrumento formulado pela United Nations Crime Institute (UNICRI), utilizado no projeto de Pesquisa de Vitimização intitulado International Crime Victimization Survey (ICVS). Também, utilizou-se como medida técnica a Pesquisa Nacional de Vitimização, realizada entre 2010-2012 nas 27 unidades da Federação com mais de 70.000 entrevistas feitas, cuja responsabilidade pela pesquisa foi da Secretaria Nacional de Segurança Pública (SENASP), do Ministério da Justiça (MJ) em consorcio com o DATAFOLHA.

Por conta das medidas conceptuais adotadas por essas pesquisas, o questionário aplicado na presente pesquisa para coleta de dados foi estruturado em oito partes intercambiadas entre si, modelo survey. A primeira 
parte toma dados sobre o "Perfil da Amostra", como Sexo, Idade, Escolaridade, Orientação Sexual, Classe Social, Renda Familiar Mensal, Tipificação Econômica Ativa, Religião, Estado Civil, Cor e Tipo de Moradia. A segunda parte, "Características das Atividades Rotineiras", em que a intenção é coletar informações sobre os Hábitos de Circulação Diária, Atividades realizadas nos últimos 30 dias e Meios de Transportes utilizados para a execução dessas atividades diárias.

A terceira parte, "Caracterização da Vizinhança" procurou obter dados sobre a vizinhança residencial e trabalhista do entrevistado, sobre o Relacionamento com os Vizinhos, a Solidariedade da Vizinhança, Características da Vizinhança, bem como sua Imagem e dos Acessos aos serviços públicos e privados. Quanto a quarta parte, "Mapeamento de Crimes", procurou obter informações sobre Furtos e Roubos de Veículos, Furto e Roubo de Objetos, Sequestro, Fraude / Estelionato, Acidentes de Transito, Agressão, Ameaça, Ofensa Sexual, Discriminação. Bem como a Taxa de Notificação e Satisfação com a Policia nos registros desses crimes.

A "Sensação de Segurança" foi tema da quinta parte do questionário, em que procurou avaliar a sensação do entrevistado em andar pelas ruas da cidade, se o entrevistado deixou de fazer alguma atividade por conta da violência, identificando assim, quem foi que deixou de fazer algo por conta da violência, e por ultimo o nível do medo sentido na vizinhança.

Nas partes seis, sete e oito do questionário dispôs perguntas que avaliavam a percepção do informante quanto a criminalidade, quanto ao risco de vitimização e sobre o funcionamento das Instituições de Policia na Segurança Pública. Em relação a "Percepção da Criminalidade", procurou saber qual a opinião do entrevistado quanto ao aumento da criminalidade na vizinhança (residencial e trabalhista); quanto a "Percepção do Risco de Vitimização" procurou saber a intensidade do medo do crime e se o 
entrevistado, por conta desse medo, se acha provável vitima da criminalidade.

Na ultima parte, "Percepção da Segurança Pública", o entrevistado foi perguntado quanto as formas de contato com a policia (Militar, na atividade ostensiva, e a Civil, na investigação), bem como a confiança que ele tem nas Policias, e se em algum momento nos últimos 12 meses ele foi vitima de violência praticada por agentes dessas policias.

Considerando que os entrevistados foram homens e mulheres Microempreendedores Individuais (CMEI), trabalhadores das Galerias Comerciais localizadas na Área Central de Manaus (AM), 42\% (n=260) são homens e 58\% (n = 358) são mulheres. O percentual dos homens entrevistados é composta assim, 8,09\% ( $n=53)$ na Galeria dos Remédios, 9,35\% ( $\mathrm{n}=78)$ na Galeria Floriano Peixoto, 11,64\% $(\mathrm{n}=67)$ na Galeria Espírito Santo e 12,92\% ( $\mathrm{n}=80)$ na Galeria Epaminondas. A amostra das mulheres entrevistadas é composta de 14,59\% ( $\mathrm{n}=102)$ na Galeria dos Remédios, 8,75\% ( $\mathrm{n}=77)$ na Galeria Floriano Peixoto, 18,80\% $(\mathrm{n}=88)$ na Galeria Espírito Santo e 15,86\% $(n=73)$ na Galeria Epaminondas.

A idade dos entrevistados, o maior percentual foram de indivíduos com idade entre 25 à 34 anos, $28 \%(n=174)$, seguido dos entrevistados com idade entre 45 à 59 anos, 26\% (n = 161), posteriomente daqueles com idade entre 16 à 24 anos, 19\% (n = 118), dos com idade entre 35 à 44 anos, $16 \%$ ( $\mathrm{n}=98)$, o menor percentual de entrevistados estã com idade entre 60 anos ou mais, $11 \%(\mathrm{n}=67)$.

Cerca de 41\% $(n=252)$ dos entrevistados possuem o Ensino Médio completo, antigo $2^{\circ}$ Grau, como grau de instrução escolar e 9\% (56) sem nenhuma instrução escolar. Quanto a $22 \%(\mathrm{n}=136)$ possuem o Ensino Fundamental completo, antigo $1^{\circ} \mathrm{Grau}$; e $28 \%$ (n = 174) obtiveram instrução 
especializada pela frequência em algum curso de graduação no Ensino Superior.

Perguntados sobre a Orientação Sexual, 53\% $(n=327)$ responderam ser heterossexuais, enquanto $29 \%(\mathrm{n}=179)$ são homossexuais, $5 \%(\mathrm{n}=31)$ são bissexuais e $13 \%(\mathrm{n}=81)$ transexuais. $O$ maior percentual de heterossexuais entrevistados encontra-se na Galeria dos Remédios, 14,16\% ( $\mathrm{n}=87)$, o menor é $12,78 \%(\mathrm{n}=79)$ pertencentes a Galeria Espírito Santo; o maior percentual de homossexuais está na Galeria Espírito Santo 9,28\% (n $=57)$ e o menor na Galeria Floriano Peixoto, 4,83\% $(\mathrm{n}=30)$. O maior percentual de bissexuais entrevistados foi na Galeria Epaminondas, 1,46\% $(n=09)$ e o de transexuais foi na Galeria Espírito Santo, 3,31\% $(\mathrm{n}=21)$.

A Classificação Social dos entrevistados, a pesquisa revela que 8\% (n $=50)$ pertencem a Classe E, já 74\% $(\mathrm{n}=457)$ pertencem a Classe C, e 18\% ( $n=111)$ estão na Classe D. Essa divisão de classe é complementada com as informações da Renda Familiar, pois considerando o valor de um salário mínimo $\mathrm{R} \$ 937,00$ (novecentos e trinta e sete reais), 4\% $(\mathrm{n}=25)$ dos entrevistados ganham até dois salários mínimos, $13 \%(\mathrm{n}=81)$ ganham mais de 10 salários mínimos, 36\% $(\mathrm{n}=222)$ ganham entre 6 à 10 salários mínimos e $47 \%(\mathrm{n}=290)$ recebem de 2 à 5 salários mínimos

Tomando por critério a auto declaração como forma de legitimidade informacional na entrevista, os entrevistados quando perquiridos sobre a que Religião cultivavam, 34\% $(\mathrm{n}=210)$ são evangélicos não pentecostais, $20 \%$ $(\mathrm{n}=123)$ evangélicos pentecostais, $14 \%(\mathrm{n}=86)$ católicos, $9 \%(\mathrm{n}=56)$ candomblé, 7\% $(\mathrm{n}=43)$ espíritas kardecistas, $6 \%(\mathrm{n}=38)$ umbanda e empatadas cada uma com 5\% (n = 31) são ateus e entrevistados que cultuam outra Religião não especificada anteriormente.

Quanto ao Estado Civil, 34\% (n = 210) dos entrevistados afirmaram estar casados, $27 \%(n=167)$ estão amigados, $22 \%(n=136)$ estão solteiros, 
10\% ( $\mathrm{n}=62)$ separados de forma não jurídica e 7\% $(\mathrm{n}=43)$ separados judicialmente. O maior percentual de entrevistados casados foi na Galeria Espirito Santo 10,44\% $(\mathrm{n}=64)$, de solteiros foi na Galeria dos Remédios 6,45\% ( $\mathrm{n}=40)$, de separados judialmente foi na Galeria Floriano Peixoto $\operatorname{com} 2,22 \%(n=13)$, de separados não judiciais foi na Galeria Epaminondas $2,75 \%(n=17)$ e de amigados na Galeria Floriano Peixoto $12,46 \%(n=76)$.

A entrevista com 618 MEI (100\%) instalados nas Galerias Comerciais da Área Central de Manaus (AM) revelou que 67\% ( $n=413$ ) residem em Cômodos tipo Kitnet, 49\% ( $\mathrm{n}=302)$ e Quarto, 18\% $(\mathrm{n}=111)$. Em Casa residem 22\% ( $\mathrm{n}=136)$ e 11\% $(\mathrm{n}=67)$ em Apartamentos da amostra pesquisada. O maior percentual de residentes em Casa estão na Galeria Floriano Peixoto 6,45\% $(\mathrm{n}=40)$, em Apartamentos está na Galeria Espirito Santo 4,29\% ( $\mathrm{n}=26$ ), em kitnet e Quarto estão na Galeria Epaminondas, respectivamente, $13,66 \%(\mathrm{n}=79)$ e $5,58 \%(\mathrm{n}=34)$.

Cerca de 76\% $(n=470)$ dos entrevistados costumam estar fora de casa entre 6:00 e 12:00 da manhã e 87\% $(\mathrm{n}=538)$ pela parte da tarde, das 12:00 às 18:00. Já $24 \%(\mathrm{n}=148)$ realizam atividades rotineiras em casa pela manhã, das 6:00 ás 12:00, e 13\% $(\mathrm{n}=80)$ estão em casa pela parte da tarde, das 12:00 às 18:00. A pesquisa revela que esse percentual sofre alteração no período da noite e da madrugada, quando 66\% $(n=407)$ dos entrevistados estão em casa das 18:00 às 24:00, aumentando esse percentual na madrugada quando estão em casa das 24:00 às 6:00 81\% $(n=500)$ dos entrevistados. Por outro lado, $34 \%(\mathrm{n}=211)$ estão fora de casa a noite das 18:00 às 24:00, diminuindo esse percentual para 19\% $(n=118)$ de entrevistados que ficam fora de casa na madrugada das 24:00 às 6:00.

Perguntados sobre quais as atividades eles realizaram fora do ambiente de trabalho nos últimos 30 dias a pesquisa revelou que $94 \%(n=580)$ saiu de casa para ir a missa, culto ou frequentou alguma atividade relacionada a Religião; 84\% $(\mathrm{n}=519)$ disse ter frequentado sessão de cinema; 77\% ( $\mathrm{n}=$ 
475) saiu para algum bar ou frequentou casa noturna; 68\% ( $\mathrm{n}=420)$ afirmaram ter frequentado praias ou balneários; $57 \%(\mathrm{n}=352)$ preferiram sair para passear no shopping Center; 42\% ( $\mathrm{n}=259)$ disse ter praticado alguma atividade esportiva; 31\% ( $\mathrm{n}=191)$ saíram para visitar parentes ou amigos; empatados com 22\% $(n=135)$ cada, estão as atividades de sair para algum evento esportivo amador ou profissional e sair para algum show, espetáculo de musica ou dança; e 19\% (n = 117) dos entrevistados disseram que frequentaram feiras populares.

Sobre os meios de transportes mais utilizados para ir ao trabalho e realizar atividades rotineiras, os participantes da pesquisa revelaram que o carro particular seguido da moto particular respectivamente com 78\% (n = 482) e $62 \%(n=383)$ são os meios de transportes mais utilizados; $36 \%(n=$ 222) usam moto-taxi; 32\% $(\mathrm{n}=197)$ ônibus; $25 \%(\mathrm{n}=154)$ dizem não utilizar meio de transporte motorizado algum preferindo ir à pé para seu trabalho ou para realizar alguma tarefa rotineira; $14 \%(n=86)$ usam bicicleta; $12 \%(\mathrm{n}=74)$ utilizam taxi como meio de transporte principal.

\section{3 - CONDICIONAMENTO PERCEPTIVO DA SEGURANÇA NA ÁREA CENTRAL DE MANAUS (AM)}

A pesquisa definiu a sensação de segurança percebida pelos trabalhadores MEI das Galerias Comerciais localizadas na Área Central de Manaus (AM) a partir da resposta de três perguntas: 1) Você se sente seguro em andar de dia e/ou noite no seu bairro e/ou no seu local de trabalho? 2) $\mathrm{O}$ que deixou de fazer por causa da violência? 3) O que mais teme no seu bairro e/ou em seu local de trabalho? Conforme tabela abaixo:

\begin{tabular}{|c|c|c|c|c|c|c|c|c|}
\hline \multirow{2}{*}{ BAIRRO } & \multicolumn{2}{|c|}{ Espírito Santo } & \multicolumn{2}{c|}{ Epaminondas } & \multicolumn{2}{c|}{ Remédios } & \multicolumn{2}{c|}{ Floriano Peixoto } \\
\cline { 2 - 9 } & Homem & Mulher & Homem & Mulher & Homem & Mulher & Homem & Mulher \\
\hline DIA & $91 \%$ & $80 \%$ & $63 \%$ & $81 \%$ & $78 \%$ & $96 \%$ & $84 \%$ & $98 \%$ \\
\hline NOITE & $32 \%$ & $12 \%$ & $46 \%$ & $9 \%$ & $59 \%$ & $28 \%$ & $51 \%$ & $10 \%$ \\
\hline
\end{tabular}

TABELA 2: SENSAÇÃO DE SEGURANÇA DE ANDAR NO BAIRRO

FONTE: Pesquisa de Vitimização MEI (2014-2015) 


\begin{tabular}{|c|c|c|c|c|c|c|c|c|}
\hline $\begin{array}{c}\text { LOCAL DE } \\
\text { TRABALH }\end{array}$ & \multicolumn{2}{|c|}{ Espírito Santo } & \multicolumn{2}{|c|}{ Epaminondas } & \multicolumn{2}{c|}{ Remédios } & \multicolumn{2}{c|}{$\begin{array}{c}\text { Floriano } \\
\text { Peixoto }\end{array}$} \\
\cline { 2 - 9 } & $\begin{array}{c}\text { Home } \\
m\end{array}$ & $\begin{array}{c}\text { Mulhe } \\
r\end{array}$ & $\begin{array}{c}\text { Home } \\
m\end{array}$ & $\begin{array}{c}\text { Mulhe } \\
r\end{array}$ & $\begin{array}{c}\text { Home } \\
m\end{array}$ & $\begin{array}{c}\text { Mulhe } \\
r\end{array}$ & $\begin{array}{c}\text { Home } \\
m\end{array}$ & $\begin{array}{c}\text { Mulhe } \\
r\end{array}$ \\
\hline DIA & $62 \%$ & $33 \%$ & $54 \%$ & $22 \%$ & $79 \%$ & $45 \%$ & $67 \%$ & $43 \%$ \\
\hline NOITE & $24 \%$ & $8 \%$ & $58 \%$ & $3 \%$ & $11 \%$ & $5 \%$ & $16 \%$ & $10 \%$ \\
\hline
\end{tabular}

TABELA 3: SENSAÇÃO DE SEGURANÇA DE ANDAR NO ENTORNO DO LOCAL DE TRABALHO

FONTE: Pesquisa de Vitimização MEI (2014-2015)

Com relação se os trabalhadores MEI homens entrevistados se sentem seguros andando de dia e/ou a noite no seu bairro ou no seu local de trabalho, 91\% da Galeria Espírito Santo, 84\% da Floriano Peixoto, 78\% da Remédios e 63\% da Epaminondas, se sentem seguros andando de dia no seu bairro. Já 79\% da Galeria dos Remédios, 67\% da Floriano Peixoto, 62\% da Espírito Santo, 54\% da Epaminondas dos homens se sentem andando de dia próximo ao seu local de trabalho. Sobre se sentir seguro andando a noite pelo bairro: 59\% da Galeria dos Remédios, 51\% da Floriano Peixoto, 46\% da Epaminondas e 32\% da Espírito Santo dos homens se sentem confortáveis e seguros andando a noite pelo seu bairro. Logo se sentir seguro andando a noite no entorno do seu local de trabalho: 58\% da Galeria Epaminondas, 24\% da Espírito Santo, 16\% da Floriano Peixoto e 11\% da Remédio dos homens se sentem seguros andando a noite pelo seu local de trabalho.

Se as trabalhadoras MEI entrevistadas se sentem seguras andando de dia e/ou a noite no seu bairro ou no seu local de trabalho: 98\% da Floriano Peixoto, 96\% da Remédios, 81\% da Epaminondas e 80\% da Espírito Santo se sentem seguras andando de dia no seu bairro. Logo, 28\% da Remédios, 12\% da Espírito Santo, 10\% da Floriano Peixoto e 9\% da Epaminondas se sentem seguras andando a noite pelo seu bairro. Com relação se sentem seguras de dia ou a noite andando no local de trabalho, 45\% da Remédios, 43\% da Floriano Peixoto, 33\% da Espírito Santo, 22\% da Epaminondas se sentem seguras andando de dia no local de trabalho. No entanto, 10\% da Floriano Peixoto, $8 \%$ da Espírito Santo, 5\% da Remédios e 3\% da 
Epaminondas se sentem confortáveis andando a noite pelo seu local de trabalho, acreditando que não vá lhe acontecer nenhum mal.

As taxas revelam que os homens entrevistados se sentem mais confiantes e seguros no entorno de suas residências durante o dia, enquanto que a noite eles são mais receosos em trafegar pelos espaços da vizinhança, por considerar que durante a noite a vizinhança se torna mais perigosa. A mesma frequência é observada entre as mulheres entrevistadas, elas se sentem mais seguras pela parte do dia, enquanto a noite a concepção de segurança baixa drasticamente, aduzindo que elas sentem mais receio em andar pela vizinhança residencial à noite do que pelo dia.

Por andar durante o dia e a noite no entorno das Galerias Comerciais onde a região é eminentemente comercial com grande movimentação de mercadorias e valores financeiros, os homens entrevistados se sentem mais seguro durante o dia em comparação com a noite, que eles se sentem mais inseguros. Com relação às respostas das mulheres entrevistadas, observa-se a ocorrência de um padrão de desconfiança por andar de dia e a noite em torno do seu local de trabalho, as taxas revelam um alto índice de mulheres que se sentem desprotegidas nas Galerias Comerciais seja de dia ou a noite.

Quando os entrevistados perguntados sobre o que eles deixaram de fazer devido a violência criminal, 95\% dos entrevistados evitaram sair portando muito dinheiro, objetos de valor chamativo; $40 \%$ evitou sair a noite ou chegar muito tarde em casa e evitou certos tipos de transportes;35\% deixou de frequentar locais públicos com pouca circulação de pessoas; 33\% deixou de ir a certos bancos ou caixas eletrônicos; 31\% evitou convivência com os vizinhos; $18 \%$ evitou ficar sozinho em casa e deixou de frequentar locais de consumo de bebidas alcoólicas, como demonstra o gráfico abaixo: 


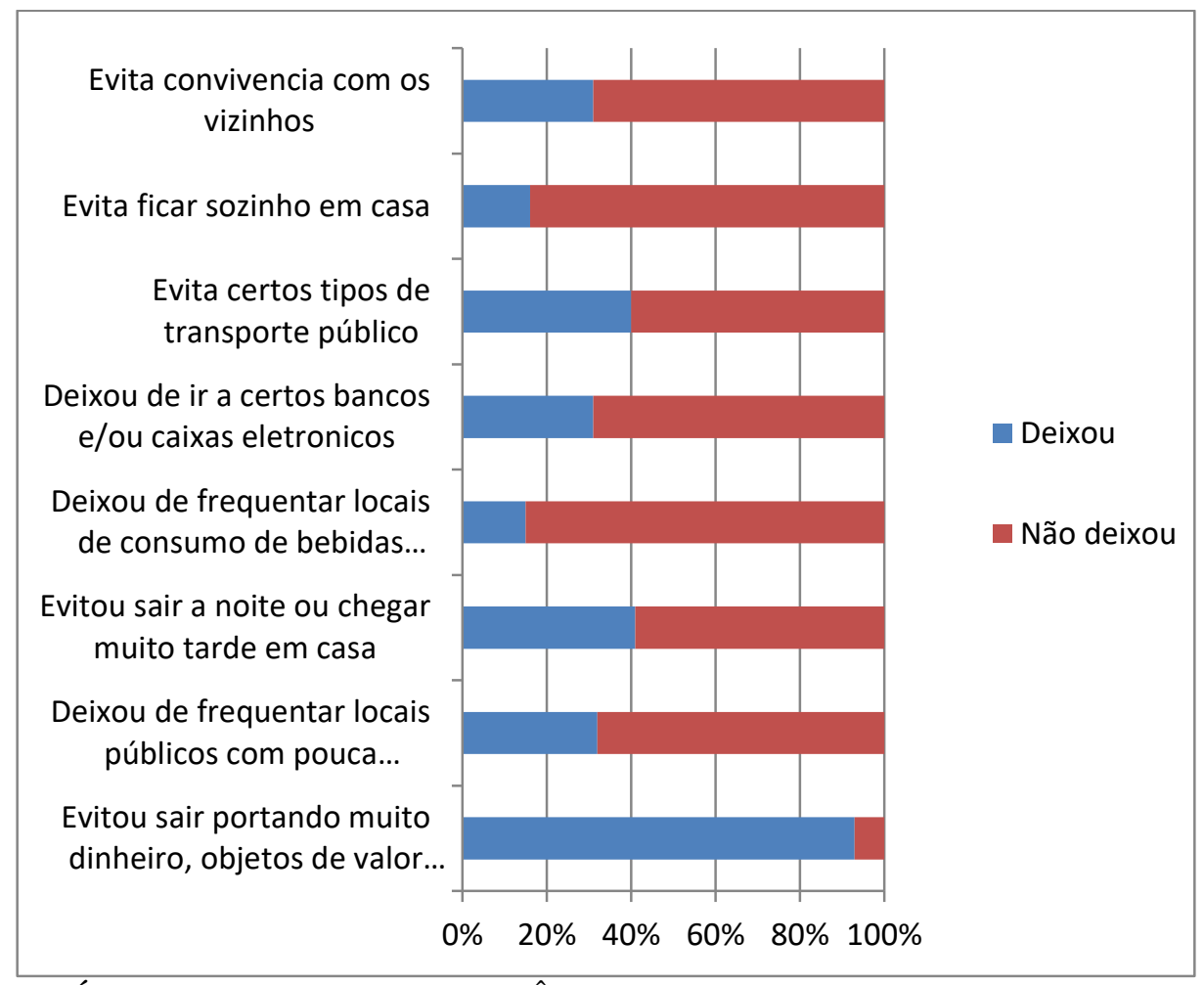

\section{GRÁFICO 1: EFEITOS DA VIOLÊNCIA NAS ATIVIDADES ROTINEIRAS FONTE: Pesquisa de Vitimização MEI (2014-2015)}

Considerando que a criminalidade tem como consequência após a instauração dos danos e perdas por conta da ação criminosa, a corporificação do medo no comportamento social do individuo pela amplificação das noções ideológicas e sociais da insegurança moral, física e patrimonial, concorda-se que o território urbano configura-se a partir da frequência da insegurança sobre o estilo de vida, nos hábitos e atividades rotineiras no cotidiano, pois o "acumulo social da violência” (MISSE, 1999) torna o crime representação do perigo eminente motivador das alterações dos modos de sociabilidade nas redes de integração social.

Assim, perguntando aos entrevistados o que eles mais temiam em seu bairro e local de trabalho, 88\% tinha medo de ser confundido como "bandido" por agentes de segurança privado e publica; 85\% ser confundido com um "desafeto" por bandidos; 81\% sofrer agressão do companheiro, 
marido ou esposa; $75 \%$ estar no meio de um tiroteio; $70 \%$ ter o carro ou moto roubada; $63 \%$ sofrer extorsão e violência da policia; $55 \%$ ser agredido fisicamente; $41 \%$ ser sequestrado, como demonstra o gráfico abaixo:

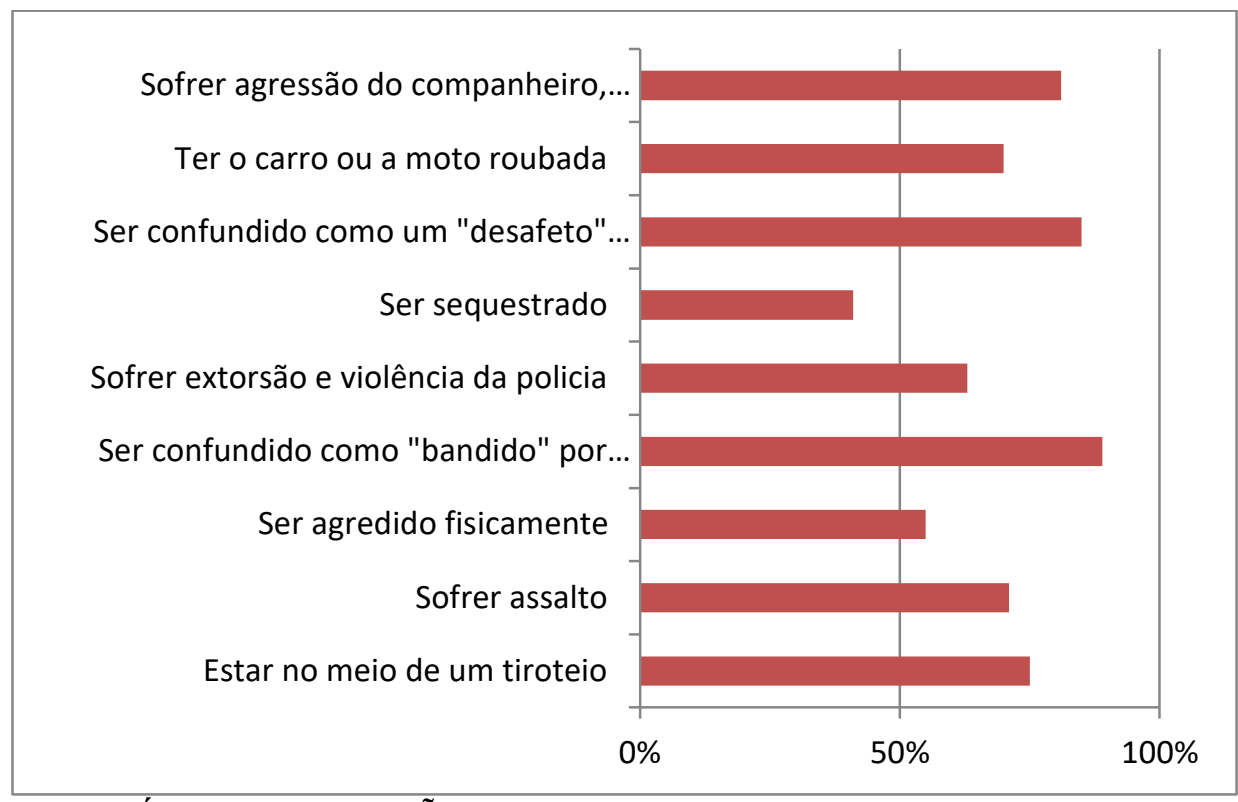

GRÁFICO 2: SITUAÇÕES DE MEDO NO BAIRRO E NO LOCAL DE TRABALHO

FONTE: Pesquisa de Vitimização MEI (2014-2015)

\section{CONSIDERAÇÕES FINAIS}

A criminalidade como fenômeno social definidor da ideia de segurança e insegurança numa sociedade é consolidada mediante estímulos sociais que favorecem a formação de condições desviantes dos valores morais e legais, observa-se que a criminalidade avaliada pelos entrevistados na formação do senso de segurança é estabelecida como um sistema social de praticas, normas e pensamentos desviantes, amparados na concepção do desvio como sintoma negativo dentro de um organismo que prejudica a integração comunitária dos entrevistados. Essa característica é vista com mais clareza quando 95\% dos entrevistados afirmam que já evitaram sair portando muito 
dinheiro, 35\% deixaram de frequentar locais públicos com pouca circulação de pessoas e $31 \%$ evitam convivência com os vizinhos, como demonstra Gráfico 1 sobre os efeitos que a violência provocou na rotina dos entrevistados

No caso em tela a integração comunitária formada por este sintoma cumpre dupla função no esclarecimento do desvio, primeiro porque o delito cometido provoca a "desregulação" como causa da baixa coesão social, isso ocorre porque as condições sociais e institucionais de segurança presentes no local de trabalho e na vizinhança residencial estimulam o afrouxamento nas tensões reguladoras das relações entre os indivíduos. Situação vista quando apenas 24\% dos homens entrevistados da Espírito Santo, 16\% da Floriano Peixoto e $11 \%$ da Remédio se sentem seguros andando a noite pelo seu local de trabalho. E 12\% das mulheres Espírito Santo, 10\% da Floriano Peixoto e 9\% da Epaminondas se sentem seguras andando a noite pelo seu bairro, dados vistos nas Tabelas 2 e 3 .

Segundo, ao criar uma aparente liberdade nas relações a "desregulação" estimula a ingerência dos comportamentos sociais ao deixalos por conta das emoções e das expectativas individuais, os indivíduos orientam suas ações em valores não acordados com outros membros da mesma sociedade, impondo uma rotina desvinculada da consciência coletiva pela execução de ações indigitadas e ao sabor das aspirações particulares. Essa "desregulação" se viu com mais clareza quando o medo da violência formata o comportamento social dos entrevistados a partir da insegurança moral, física e patrimonial, que por exemplo, $88 \%$ tem medo de ser confundido como "bandido" por agentes de segurança privado e publica; $85 \%$ ser confundido com um "desafeto" por bandidos; $81 \%$ sofrer agressão do companheiro, marido ou esposa, como demonstra o Gráfico 2.

A “desregulação social” provocada pela criminalidade e influente na coesão social entre os entrevistados da pesquisa enfraquece os modos de 
controle social e a conformação dos indivíduos às rotinas que tentam se desviar das praticas delitivas e do contexto de ocorrência criminal presente na Área Central, bem como próximo das residências dos participantes da pesquisa. Porque a desregulação é aprimorada em desorganização e dividida em dois aspectos, um social e outro físico, a conjugação dos dois elementos dá sentido de desorganização do espaço social, tornam-se causas dos efeitos da violência e do medo do crime na vida do entrevistado, pois motiva o menor ou maior controle da criminalidade que estimula o senso de segurança ou não do lugar.

Como se observa nos dados coletados a criminalidade reorienta a ordem de um lugar, independente de sua intensidade, tem a capacidade de estimular novos fatos desestabilizadores dependentes ou não do primeiro fato, porque a ideia estimulante presente nos novos fatos é a de que pequenos atos interpretados "desordem" indicariam descompromisso dos indivíduos pelo lugar, desse modo o desvio provocado pela transgressão teria relevância perceptiva para aquela população daí da reduplicação da "desordem" até atingir a banalização da transgressão como ação social suplementar do individuo na Sociedade e da percepção individual da segurança.

\section{REFERÊNCIAS}

BEATO, Claudio. Determinantes da criminalidade em Minas Gerais. Revista Brasileira de Ciências Sociais. ANPOCS, São Paulo, n. 13, v. 37, jun. 1998, pp. 74-87.

CATÃO, Yolanda. Pesquisa de Vitimização. In.: CERQUEIRA, D.; LEMGRUBER, J.; MUSUMECI, L. (org.) Fórum de debates criminalidade, violência e segurança pública: uma discussão sobre as bases de dados e questões metodológicas. Rio de Janeiro: Ipea/CESECUCAM, 2000. 
CERQUEIRA, D.; LOBÃO, W.; CARVALHO. A. O jogo dos sete mitos e a miséria da segurança pública no Brasil. Brasília: IPEA. N. 1144, dez. 2005.

COHEN, Lawrence; FELSON, Marcus. Social change and crime rate trends: a routine activity approach. American Sociological Review, n. 44, p. 568-608, 1979.

KAHN, Tulio. Medindo a criminalidade: um panorama dos principais metodos e projetos existentes. In.: CERQUEIRA, D.; LEMGRUBER, J.; MUSUMECI, L. (org.) Fórum de debates - criminalidade, violência e segurança pública: uma discussão sobre as bases de dados e questões metodológicas. Rio de Janeiro: Ipea/CESEC-UCAM, 2000.

LANGTON, L. et al. Victimizations not reported to the police, 20062010, U.S. Department of Justice Office of Justice, Programs Bureau of Justice Statistics, 2012.

MACHADO DA SILVA, Luis Antonio. Violência Urbana, sociabilidade violenta e agenda pública In: MACHADO DA SILVA, L.A (org.), Vida sob cerco, Violência e Rotina nas favelas do Rio de Janeiro, Nova Fronteira, 2008.

MAGUIRE, M. Crime statistics: the data explosion and its implications. The Oxford HandBook of Criminology. New York: Oxford University Press, 2002.

MISSE, Michel. Malandros, marginais e vagabundos \& a acumulação social da violência no Rio de Janeiro. Rio de Janeiro, 1999. Tese (Doutorado em Ciências Sociais) - Instituto Universitário de Pesquisas no Estado do Rio de Janeiro / Universidade Candido Mendes (IUPERJ/UCAM).

MOSHER, C.; MIETHE, T.; PHILLIPS, D. The mismeasue of crime. California: Sage Publications, 2002.

NASCIMENTO, Antônio Gelson de Oliveira. Evolução do impacto das mortes por causas violentas na esperança de vida da população de Manaus entre 1980 e 2009.Minas Gerais, 2011. Tese (Doutorado em Demografia) - Universidade Federal do Minas Gerais (UFMG).

NEWMAN, Oscar. Defensible space: crime prevation throughurban design. New York: Macmillan, 1972. 
PINTO, A.S.; MELO, D.L.B; AZEVEDO, J. Desenvolvimento de metodologia e aplicação de pesquisa de vitimização na região metropolitana do Rio de Janeiro, $31^{\circ}$ Encontro Anual da ANPOCS, Caxambu, Minas Gerais, 2007.

REPPETTO, Thomas A. Residential crime. Chicago: Ballinger Publishing Company, 1974.

SECRETARIA NACIONAL DE SEGURANÇA PÚBLICA (SENASP). Pesquisa nacional de vitimização. Brasília: Ministério da Justiça, 2012.

SILVA, B. Coesão social, desordem percebida e vitimização em Belo Horizonte, Minas Gerais, Brasil. Belo Horizonte, 2004. Dissertação (Mestrado) - Faculdade de Filosofia e Ciências Humanas da UFMG.

VAN DIJK, J.et al. Criminal victimization in international perspective: key findings from the 2004-2005 ICVS and EU-ICS. United Nations Office on Drugs and Crime, 2008

VELHO, Gilberto. O desafio da violência. Estudos Avançados, São Paulo, n. 14, p. 56-60, 2000.

WAISELFISZ, Julio Jacobo. Mapa da violência III. Rio de Janeiro: Instituto Sangari, 2013.

Mapa da violência. Rio de Janeiro: Instituto

Sangari, 2014.

ZALUAR, Alba. Um debate disperso: violência e crime no Brasil da redemocratização. São Paulo em Perspectiva, São Paulo, v. 13, n. 3, p. 3$17,1999$.

ZILLI, L. F. O Bonde tá Formado: gangues, ambiente urbano e criminalidade violenta. Belo Horizonte, 2011. Tese (Doutorado) Departamento de Sociologia e Antropologia, Universidade Federal de Minas Gerais (UFMG). 